\title{
Why Can't We Be More Idiographic in Our Research?
}

\section{Citation}

Barlow, David H. and Matthew Nock. 2009. Why can't we be more idiographic in our research? Perspectives on Psychological Science 4(1): 19-21.

\section{Published Version}

doi:10.1111/j.1745-6924.2009.01088.x

\section{Permanent link}

http://nrs.harvard.edu/urn-3:HUL.InstRepos:4133809

\section{Terms of Use}

This article was downloaded from Harvard University's DASH repository, and is made available under the terms and conditions applicable to Open Access Policy Articles, as set forth at http:// nrs.harvard.edu/urn-3:HUL.InstRepos:dash.current.terms-of-use\#OAP

\section{Share Your Story}

The Harvard community has made this article openly available.

Please share how this access benefits you. Submit a story.

\section{Accessibility}


Why can't we be more idiographic in our research?

David H. Barlow

Boston University

Matthew K. Nock

Harvard University 


\begin{abstract}
Most psychological scientists make inferences about the relations among variables of interest by comparing aggregated data from groups of individuals. Although this method is unarguably a useful one that will continue to yield scientific advances, important limitations exist regarding the efficiency and flexibility of such designs, as well as with the generality of obtained results. Idiographic research strategies, which focus on the intensive study of individual organisms over time, offer a proficient and flexible alternative to group comparison designs; however, they are rarely taught in graduate training programs and seldom used by psychological scientists. We highlight some of the unique strengths of idiographic methods, such as single case experimental designs, and suggest that psychological science will progress most efficiently with an increased use of such methods in both laboratory and clinical settings.
\end{abstract}


Edward Tolman said to Gordon Allport "I know I should be more idiographic in my research, but I just don't know how to be," to which Allport replied, "let's learn!" (Allport, 1962, p. 414). This sentiment was based on the fact that, whether it's a laboratory rat, or a patient in the clinic with a psychological disorder, it is the individual organism that is the principle unit of analysis in the science of psychology. The intensive study of the individual is associated with a hallowed tradition in scientific psychology. Indeed the founders of experimental psychology including Fechner, Wundt, Ebbinghaus, and Pavlov studied individual organisms with scientific approaches that would be considered internally valid, and strengthened these findings (and began to establish generality) through replication in other organisms (see Barlow, Nock, \& Hersen, 2008).

This scientific strategy, which is fully capable of establishing causal relations among variables, came to be known as the "idiographic" approach. Gordon Allport, in his area of social psychology, argued eloquently that the science of psychology should attend to the uniqueness of the individual organism (Allport, 1962). Routed deep in the in the structural school of psychology, this approach also was popular in more applied branches in psychology in the middle of the last century. Perhaps the champion of an idiographic approach in clinical settings was Shapiro, who has early as 1951 was advocating a scientific approach to the study of individuals with psychopathology (e.g. Shapiro 1961, 1966). The idiographic approach perhaps reached its zenith in psychological science with the work of B.F. Skinner. In a famous quote Skinner (1966) noted: “...instead of studying a thousand rats for one hour each or a hundred rats for ten hours each the investigator is more likely to study one rat for a thousand hours" (p. 21). Thus, Skinner and his colleagues in the animal laboratories are largely credited with 
developing and refining an experimental idiographic approach that came to be known as the experimental analysis of behavior.

This idiographic approach represents a true scientific undertaking since independent variables are manipulated in the context of carefully measured and repeatedly assessed dependent variables. This is in contrast to the alternative experimental strategy usually referred to as "nomothetic," which looks to assemble relatively large groups of individual organisms and in the most straightforward application examines the average response of the group to the introduction of some manipulation compared to well-construed control conditions. The major differences between the idiographic and nomothetic traditions are, of course, approaches to intersubject variability and the generality of findings. Since variability is often considerable among organisms, the task of any psychological scientist is to discover functional relations among independent variables over and above the welter of environmental and biological variables influencing the organism at any given point in time. A nomothetic approach makes an implicit assumption that much of this variability is intrinsic to the organism and uses sophisticated data analytic procedures to look for reliable effects over and above this "error." Significant effects are then assumed to be more or less generalizable based on the number of individuals included in the experimental group and the representativeness of the population of such individuals (i.e., the use of random sampling).

Of course, random sampling is seldom achieved in psychological research where, indeed, the goal is more often to strive for homogeneous samples in which the generality 
of findings can be very limited. As Sidman (1960) pointed out a number of years ago in discussing approaches to variability:

"The rationale for statistical immobilization of unwanted variables is based on the assumed random nature of such variables. In a large group of subjects, the reasoning goes, the uncontrolled factor will change the behavior of some subjects in one direction and will affect the remaining subjects in the opposite away. When the data are averaged over all the subjects, the effects of the uncontrolled variables are presumed to add algebraically to zero. The composite data are then regarded as though they were representative of one ideal subject who had never been exposed to the uncontrolled variables at all” (p. 162).

Addressing the issue of the generality of findings, Sidman notes in the same source: "Tracking down sources of variability is then a primary technique for establishing generality. Generality and variability are basically antithetical concepts. If there are major undiscovered sources of variability in a given set of data, any attempt to achieve subject or principle generality is likely to fail. Every time we discover and achieve control of a factor that contributes to variability, we increase the likelihood that our data will be reproducible with new subjects and in different situations. Experience has taught us that precision of control leads to more extensive generalization of data" (p. 152).

Although the use of the idiographic approach led to significant advances in the earliest days of laboratory-based experimental psychology, as well as during early translations of findings from psychological science to clinical applications in the middle of the last century, it is clear that over the past few decades the nomothetic strategy has 
become dominant as a method to establish both internal and external validity (Kazdin, 2003; Nock, Janis, \& Wedig, 2008). One reason for this development in applied settings was the beginning of funding of large randomized clinical trials (RCTs) by the National Institutes of Health.

Many such studies require $>10$ years and many millions of dollars to perform one treatment trial. For instance, the National Institutes of Mental Health (NIMH) funded the treatment of depression collaborative research program (Elkin et al., 1989). This study, which took 13 years to finish (1977-1990), was reminiscent of earlier efforts such as the Cambridge Somerville Youth Study conducted from 1935 through 1951, which divided delinquent boys into two groups - one treatment group and one who received "treatment as usual" (McCord, 1978). The fact that there were no effects at five, 10, 20, or 30 years did much to discourage efforts of this type for at least the next thirty years. In fact, results from the NIMH depression collaborative trial were not particularly revealing either since no significant differences existed among treatment and comparison groups at any point in time. Nevertheless, this trial provoked useful comment and a great deal of controversy focused on strategic issues and the potential for improvement in the methodology of RCTs. These trials have improved to the point where they have become "the gold standard" for establishing causal relations between independent and dependant variables more generally and data emanating from these trials have deep influences on health care practices (Barlow, 2004).

But is something still lacking? Scientifically, relying on a relatively small group of researchers requiring enormous amounts of time and resources to perform a single treatment trial can be seen as an inefficient method of advancing knowledge. In applied 
clinical settings, clinicians often question the applicability of findings from RCTs to individuals seen in typical clinical settings. In other words, there is a strong perception that problems exist in generalizing a nomothetic result to an idiographic situation. The variety of forms that these arguments take are often cast as specific objections to RCT methodology, and these arguments have been detailed numerous times in the past decade (e.g., Persons \& Silberschatz, 1998; Westen, Novotny, \& Thompson-Brenner, 2004). Rather than simply critiquing nomothetic methodologies, can we enrich these methodologies with a complimentary focus on the individual? The fact is that we have a good idea of how to be more idiographic in our research. While most psychological researchers have been trained in and have relied primarily on group comparisons designs, exciting advances have been made in the use of idiographic methodologies, such as the single-case experimental design (see Barlow, Nock, \& Hersen, 2008). The flexibility and efficiency of these designs make them ideally suited for use by psychological scientists, clinicians, and students alike given they require relatively little time, resources and subjects and yet can provide strong evidence of causal relations between variables.

The time now seems right to put more emphasis on idiographic strategies that can be integrated in a healthy way into existing nomothetic research approaches in both clinical and basic science settings. In clinical science, having established the effectiveness of a particular independent variable (e.g., an intervention for a specific form of psychopathology) one could then carry on with more idiographic efforts tracking down sources of intersubject variability and isolating factors responsible for this variability (Kazdin \& Nock, 2003; Nock, 2007). Necessary alterations in the intervention protocols to effectively address variability could then be tested, once again idiographically, and 
incorporated into these treatments. In basic science laboratories rather than tolerating large error terms, similar strategies could be undertaken. Thus would all psychological science, both basic and applied, benefit.

\section{Footnote}

Correspondence concerning this article should be addressed to David H.

Barlow, Center for Anxiety and Related Disorders, Boston University, 648

Beacon St., 6th Floor, Boston, MA 02215-2013. E-mail: dhbarlow@bu.edu 


\section{References}

Allport, G.D. (1962). The general and the unique in psychological science. Journal of Personality, 30, 405-422.

Barlow, D.H. (2004). Psychological treatments. American Psychologist, 59 (9), 869 878 .

Barlow, D.H., Nock, M.K., \& Hersen, M. (2008). Single case experimental designs: Strategies for studying behavior change ( $3^{\text {rd }}$ edition). Boston, MA: Allyn and Bacon.

Elkin, I., Shea, M.T., Watkins, J.T., Imber, S.D., Sotsky, S.M., Collins, J.F., et al. (1989). National Institute of Mental Health Treatment of Depression Collaborative Research Program. General effectiveness of treatments. Archves of General Psychiatry, 46 (11), 971-982; discussion 983.

Kazdin, A.E. (2003). Research design in clinical psychology (4 $4^{\text {th }}$ edition). Boston, MA: Allyn and Bacon.

Kazdin, A.E., \& Nock, M.K. (2003). Delineating mechanisms of change in child and adolescent therapy: methodological issues and research recommendations. Journal of Child Psychology and Psychiatry, 44 (8), 1116-1129.

McCord, J. (1978). A thirty-year follow-up treatment effects. American Psychologist, 33 (3), 284-289.

Nock, M.K. (2007). Conceptual and design essentials for evaluating mechanisms of change. Alcoholism: Clinical and Experimental Research, 31, 4S-12S.

Nock, M.K., Janis, I.B., \& Wedig, M.M. (2008). Research design. In A.M. Nezu \& M. Nezu (Eds.), Evidence -based outcome research: A practical guide to conducting randomized controlled trials for psychosocial interventions (pp. 201-218). New York: Oxford University Press.

Persons, J. B., \& Silberschatz, G. (1998). Are results of randomized controlled trials useful to psychotherapists? Journal of Consulting and Clinical Psychology, 66 (1), 126.135 .

Sidman, M. (1960). Tactics of scientific research: Evaluating experimental data in psychology. New York: Basic Books.

Skinner, B.F. (1966). Operant behavior. In W.K. Honig (Ed.), Operant behavior: Areas of research and application (pp. 12-32). New York: Appleton-Century-Crofts. 
Westen, D., Novotny, C.M., \& Thompson-Brenner, H. (2004). The empirical status of empirically supported psychotherapies: Assumptions, findings, and reporting in controlled clinical trials. Psychological Bulletin, 130 (4), 631-663. 